\title{
9
}

\section{Tales from the Trenches: Zooming in on the Process of Desistance from Sexual Offending}

\author{
Danielle Arlanda Harris
}

\section{Introduction}

Almost everyone who is incarcerated is one day released back into the community (Petersilia, 2004). This is just as true for sexual offenders as it is for their non-sexual-offender counterparts, but their experiences of release and reentry tend to be monitored considerably more closely. Given the undeniable gravity and significant social costs of child sexual abuse (in particular), it is essential that we are as well informed as possible about what helps and what hinders the successful community re-entry of the perpetrators of these offences. It is also necessary to identify not just the factors that reduce recidivism, but also the factors that maximize desistance from offending and prevent sexual victimization.

Sexual offending research is now a well-established area of study, but the dynamic nature of a sex offender's criminal career has only recently attracted research attention, and we know comparatively little about the mechanisms of desistance from sexual offending. We do know that desistance is not a new phenomenon.

Criminologists have observed its existence for centuries (Laws and Ward, 2011; Sampson and Laub, 1993): most individuals with criminal histories eventually stop offending (Göbbels et al., 2012; Maruna, 2001). Decades of mostly psychological research on sexual offending consistently show that risk declines with age, and recidivism is lowered when treatment and social supports are available (Scoones et al., 2012). Without labelling it so, the empirical reality of low sexual recidivism is essentially evidence of desistance. What is new is the recent reframing of sexual offending within the language of desistance (Farmer et al., 2011; Laws and Ward, 2011; Willis et al., 2010). The central aim of the present study was to contribute to this growing body of literature and examine the nature and extent of desistance from sexual offending in a sample of men convicted of sexual offences and recently released from custody. 


\section{Desistance defined}

Desistance has been described in a number of ways, but generally refers to a slowing down or stopping of offending behaviour (Farrall, 2010). Operationalizations have included a gradual slowing down of criminal behaviour, a marked decrease in the frequency, intensity, and seriousness of criminal behaviour, the absence of official charges or convictions, and the self-report of the complete termination of criminal behaviour (Willis et al., 2010). The present study adopts Laws and Ward's (2011) definition that desistance is a dynamic process that includes stopping and refraining from a behaviour.

Defining its temporal parameters remains one of the most contentious issues in the study of desistance, with researchers varying widely on how much time free from criminal activity constitutes desistance. For instance, criminologists have argued that 12 months of crime-free street time is sufficient (Graham and Bowling, 1995, in Healy, 2010), and also that a follow-up of 2 years is necessary to capture reconvictions (Cann et al., 2004, in Healy, 2010). It is also generally agreed by psychologists that due to their apparently different criminal careers (Hanson, 2002) sex offenders require a longer period of time in which to exhibit desistance. (Recommendations have ranged from 3 to 6 years, Farrall et al., 2011.) Many of the participants in the present study were over 50 years of age at the time of their interview and had been out of custody for up to 15 years. Although one cannot be truly certain of desistance until death (Maruna, 2001), the characteristics of the present sample provided an ample window of time in which to detect self-reported abstinence from offending.

\section{Public perceptions of desistance and recidivism}

Sex offenders have been all but ignored by previous well-known studies of desistance (Farrall et al., 2011). Such enquiries either did not distinguish between sexual and non-sexual offenders (Laub and Sampson, 2003; Maruna, 2001) or, even more curiously, explicitly excluded sexual offenders from their studies without explanation (e.g., see Healy, 2010). A potential reason for this neglect may be the enduring but largely inaccurate assumption that sex offenders rarely, if ever, desist. Over the last decade, distinct but complementary perspectives from multiple disciplines have converged to examine sexual offending, but erroneous assumptions that sex offenders will never stop have endured (Willis et al., 2010).

More than any other type of offender, those convicted of sexual crimes (particularly against children) are now subject to specific, expansive, discretionary, and controversial legislation that has impacted decision-making at 
almost every stage of the criminal justice system (Harris et al., 2009; Janus and Walbek, 2000; La Fond, 2000; Simon, 1997a; Willis et al., 2010). These laws are aimed directly at sexual offenders returning to the community and rest upon the erroneous but tenacious assumption that all sexual offenders constitute a homogeneous group that remain at a considerable risk of recidivism for the remainder of their lives. Various pieces of memorial legislation passed haphazardly in honour of specific victims of horrific crimes now restrict profoundly the lives of an already disenfranchised population of offenders. These policies most notably include community registration and/or notification and residence restrictions (Jeglic et al., 2012).

Community notification

Legislation that provides for community notification or registration now exists in some form in all 50 states of the US (Jeglic et al., 2012; Lieb et al., 1998). The spectrum is vast. For example, the Office of the Attorney General maintains a publicly available website that contains names, addresses, and photographs of convicted sexual offenders (www.meganslaw.ca.gov). Several states (including Texas, Florida, and Louisiana) have introduced more specific requirements, including the use of signs in front of one's house, labels on clothing, and vehicle bumper stickers (Petrunik, 2002). Advocates of community notification initiatives have argued that telling the public about sexual offenders who live in their community empowers individuals to take action to protect themselves and their families (Finn, 1997).

Known more commonly as Megan’s Law, the original legislation was enacted and named for Megan Kanka who, in 1994, was raped and murdered by Jesse Timmendequas, a convicted child molester who lived across the street (Janus and Walbek, 2000; Jeglic et al., 2012). The impetus for the legislation stemmed from her parent’s belief that Megan's death could have been prevented had they known of Timmendequas' existence and location.

The focus of this legislation on sexual offenders increases the likelihood of vigilantism by raising levels of community fear and anxiety (Lieb et al., 1998) and has the unintended consequence of making individuals complacent about their safety. Unfortunately, this false sense of security extends to the criminal justice system (Lieb et al., 1998). For example, when a child goes missing or a sexual crime is committed, searches are often narrowed to the pool of registered sex offenders (Simon, 2000). In the past this has impeded investigations and increased the danger for potential victims (Francis and Soothill, 2000). The criminal versatility of sexual offenders that is demonstrated in each of the 3 present studies should remind us that a convicted sex offender is no more likely to 
commit a sexual offence than a convicted murderer, armed robber, or car thief (Simon, 2000). These arguments suggest that 'registering the whereabouts of one [sexual offender] will not solve the crime problem in general, nor will it solve particular crimes’ (Simon, 1997b, p. 394).

The effect of the assumption of specialization and recidivism on this kind of policy has been investigated by Francis and Soothill (2000). They conducted a 21-year follow-up study of the 7,442 men convicted of sexual offences in England and Wales in 1973. One of the objectives of their study was to explore escalation by determining how many of the individuals went on to commit murder. Based on type of first conviction and subsequent arrests, they concluded that such innovations as increased surveillance, home visits, and intensive correctional supervision actually had little impact on the prevention of homicide (Francis and Soothill, 2000). Sexual offenders were indeed at a higher risk of committing homicide (by a factor of 7 when compared with the general population). But, the convicted child molesters (who would have been subject to the provisions of Megan’s Law) who did commit murder were actually more likely to kill adult women (Francis and Soothill, 2000). This provides more evidence that Megan’s Law is not particularly helpful anyway.

\section{Residence restrictions}

Jessica’s Law is a more recent development in the US, which, among other provisions, restricts where a convicted sexual offender may live upon re-entry into the community. In February 2005, 9-year-old Jessica Lunsford was abducted, raped, and 3 days later bound and buried alive (where she suffocated) by registered sex offender, John Couey. Couey lived in a trailer across the street from her home in Florida. In response to this horrific event, State Governor Jeb Bush proposed legislation that would require that anyone convicted of a single serious sexual offence against a child would be given a mandatory minimum sentence of 25 years in a maximum-security prison. The Bill proposed that upon completion of their sentence all such offenders would be followed by electronic monitoring for life. Various iterations of the law also prohibit released sexual offenders from living within 2,000 feet of a school, park, day-care centre, or school bus stop (Jeglic et al, 2012). The Jessica Lunsford Act was passed in November 2005. Since that time, 42 states have enacted some form of the Jessica Lunsford Act into law.

Although their superficial objectives are to improve community safety, when considered in light of recent research, these policies and laws are fundamentally flawed. Again, this amounts to a massive commitment to a policy that addresses the rarest of circumstances. Further, the considerable burden that these laws place on police, 
parole, and probation officers needs to be considered. Finally, restricting available accommodation for an already disenfranchised population of individuals has had the unfortunate consequence of a marked increase in homelessness (as is the case in San Francisco and Miami), not to mention elevating their likelihood of reoffending.

\section{Theories of desistance}

A range of theories of desistance have been developed largely under the umbrella of developmental and life course criminology. This body of knowledge adopts a sociological perspective and focuses on general, non-sexual desistance. These ideas can be sorted into 3 main perspectives (Healy, 2010): natural desistance or maturation, cognitive transformation or personal agency, and the achievement of informal social controls (Maruna, 2001; Sampson and Laub, 1993). Although empirical research supports these claims for both non-sexual and non-violent offenders (Maruna, 2001; Sampson and Laub, 1993), the extent to which these perspectives apply to men convicted of sexual violence remains unknown. Below, each theory is described briefly and its possible relevance to sexual aggression is discussed. (For a more detailed review of these theories, interested readers are referred to Harris, 2014a).

\section{Natural desistance}

Natural desistance is generally conceived of as a decline in or abstinence from offending that transpires independently of the actions or influence of institutions of formal or informal social control (Göbbels et al., 2012; Laws and Ward, 2011). Crime is a youthful behaviour (Wilson and Herrnstein, 1985), and this theory emphasizes the biological process of maturation and aging. The effect of age on recidivism is important for both criminal prediction in general (Wilson and Herrnstein, 1985) and sexual recidivism in particular (Barbaree and Blanchard, 2008). Although it is clearly established that there is an overall lowering of recidivism at older ages, the interpretation of this effect remains somewhat problematic for sexual offenders. Multiple explanations have been proposed, including maturation effects, changing life circumstances, declining testosterone (Barbaree and Blanchard, 2008), and differential effects of aging in and out of prison (Knight and Thornton, 2007).

\section{Cognitive transformation}

The second model of desistance describes the power of personal agency and cognitive transformation in one's life, implying a conscious decision (and ability) to change (Giordano et al., 2002). Whether gradual or instantaneous, this process of identity transformation involves 'knifing off' - a rational decision to separate one’s criminal past from 
their law-abiding future (Giordano et al., 2002). The process often includes the reconstruction of the past into a positive, redemptive narrative (Healy, 2010), most notably described through stirring tales of deliberately moving away from crime and overcoming obstacles to community reintegration (Giordano et al, 2002).

\section{Informal social control}

The obtainment of informal social controls, most often in the form of a stable marriage and a good career, is an especially well-regarded criminological theory that accounts for continuity and change in offending over time. Most notably espoused by Sampson and Laub (1993), the development of particular stakes in conformity and community investment is favoured as a mechanism of desistance over the impact of negative reinforcement, retribution, and deterrence. This theory is demonstrative of the interdisciplinary nature of sexual offence research because it aligns closely with the good lives model (Ward and Marshall, 2004) as well as the psychological literature on healthy selfesteem where the pursuit of mastery and intimacy are highlighted (McAdams, 1993).

\section{Method}

\section{Participants}

The sample of 44 men was drawn from a larger group of 50 people ${ }^{1}$ who were interviewed in 2011 and 2012 in the north eastern United States. All participants had completed a custodial sentence for a serious contact sexual offence and were now participating in outpatient therapy.

Consistent with much research on this population, the men in the sample were mostly white (89\%) with an average age of 49.3 years (range $=24-79$ years). Their most recent custodial sentence length was approximately 7 years (range $=3$ months to 30 years) for a serious sexual offence, and all participants had been living in the community for a mean of 2 years (range $=4$ months to 15 years). All participants denied offending sexually since their most recent release and could read at a fourth grade level. The men agreed to participate on the promise of anonymity, so it was not possible to access their official records to verify their offending histories or to assess their risk of reoffending using extant actuarial tools. According to their outpatient therapists, however, the men in the

\footnotetext{
${ }^{1}$ The 6 individuals who were excluded from the study were 4 men who had committed non-contact sexual offences exclusively (such as possession of child pornography); 1 man who had only been out of custody for 2 weeks (and was therefore considered unable to demonstrate any meaningful pattern of desistance) and; 1 woman who, as the only female participant, was subsequently excluded from further analysis.
} 
sample constituted a fairly low risk of reoffending upon release. Participants are identified throughout by a case number to protect their identities. Table 1 provides basic descriptive statistics for each participant including age, race, offence type, sentence length, and time since release from custody.

Participants were recruited in 1 of 2 ways. During the first wave of data collection, in 2011, therapists in cooperating outpatient programmes announced the study in their group therapy sessions and the first names and contact phone numbers of interested participants were forwarded to the author. In 2012, during the second wave of data collection, the author visited various group therapy sessions herself, described the study in person, and scheduled interviews on the spot.

\section{Procedure}

The semi-structured, individual, face-to-face interview lasted approximately 90 minutes and followed McAdams's (1993) Life History Interview Protocol. ${ }^{2}$ Interviews were conducted individually in a private office at a church, at various probation departments, and in office suites. All participants were assured of confidentiality and consented to having their interviews digitally recorded. Participants were informed that their involvement in the study would have no bearing on their probation or parole status and would not impact their progress in outpatient treatment. Participation was voluntary and participants received a \$25 gift card for a local grocery store or pharmacy for their cooperation. The study received the approval of the San Jose State University (SJSU) Institutional Review Board and was conducted in accordance with its recommendations and guidelines regarding the protection of vulnerable human subjects.

\section{Analytical strategy}

The interviews were transcribed, coded, and, analysed using qualitative narrative analysis (Atkinson, 1998). Consistent with previous approaches (Atkinson, 1998; McAdams, 1993), the interviews were transcribed verbatim in order to preserve the participant's speech. ${ }^{3}$ Each transcript was then checked back against the original audiorecording for accuracy by the author.

\footnotetext{
${ }^{2}$ See also Maruna (2001) which was later adapted for use with sex offenders by Laws and Ward (2011).

${ }^{3}$ For example, where appropriate, 'gonna' was used instead of 'going to'. Significant pauses and relevant non-verbal actions (e.g., pounding on desk for emphasis, wiping away tears) were noted in the transcripts. Unless they were excessive, verba 1 ticks or speech fillers (such as 'um', 'like', or ' $y$ 'know') were retained. Dialect and accent were noted when central to the content of the discussion.
} 
Similar to the method described by Farmer et al. (2011), data analyses focused on exploring the postrelease experiences of the participants as well as emphasizing the descriptions that participants provided about their experiences and the ways in which they understood the meaning of their own behaviour. Interview transcripts were coded by 3 independent raters, (trained graduate students) using the NVivo software program (Version 10). Coders categorized participants’ speech into various themes of desistance (articulated in the theories described above). Emergent themes of both success in and obstacles to re-entering the community and living offence-free lives were also considered.

Themes were identified when multiple accounts contained the same or similar experience or feeling. To ensure accuracy, themes were only recorded if they were identified by at least 2 independent raters and discovered in at least 2 unique transcripts. Consistent with Becker’s (1998) comments on qualitative analysis, both positive and negative themes of desistance were coded. ${ }^{4}$

\section{Results}

\section{Evidence of natural desistance}

Only 6 individuals (13.6\%) in the sample offered age or maturation as the reason they no longer offended. The following excepts demonstrate their fatigue and decision to leave their offending lives behind them:

It's just not in me no more. I'm too old ... I got tired of fighting, y’know? (B8)

I'm tired of living that kind of lifestyle. I'm getting older. I'm a grandfather. I want to have a different lifestyle, at least for the rest of the years that I have left in my life. (B7)

The men who talked about aging out of crime did so in very typically criminological ways. They were all cafeteriastyle offenders (Klein, 1984) who onsetted early, engaged in persistent and varied offending (including drugs, property, and non-sexual violent crime), and spent much of their adolescence and early adulthood in and out of institutions.

\footnotetext{
${ }^{4}$ Positive themes refer to occasions when positive evidence of the presence of the theories anticipated was identified. Negative themes instead refer to cases where there is evidence of the opposite condition of the expected theme. The absence of a theme (i.e.,, if a participant simply does not mention a theme or its opposite) is not included.
} 
I was in and out for a lot of charges. I mean, charges that I can't even remember because I know I got a long record. (B8)

All of these participants conceptualized their sexual offences as just another line on their rap-sheet. Only 1 man had graduated high school and none had ever held a job for very long. They reported multiple short-term relationships, 4 had fathered children (for whom they were never active parents) and 2 had babies on the way (both with girlfriends they were no longer dating).

Of these men, 3 could be characterized as Romeo and Juliet offenders, each having victimized an underage girl (who was only a few years their junior) within the context of a relationship:

I would like to [characterize the offence as a relationship], but [therapist] and [probation officer] say 'no', I mean, y'know, that I still groomed her or whatever. But no matter how much they tell me, that's not how I think about it ... That was the first girl I had every felt anything for. (M7)

None of the natural desisters identified as sex offenders (as many of the other men did). They also resented being forced to attend treatment, asserting repeatedly that they were not like the other sex offenders in their group and did not warrant the specialized therapy to which they had been referred.

I'm not the regular case that's here ... I feel like I've paid for that mistake ... But, if this [outpatient group therapy] is another step in me being totally free, than that's what it is. Do I like it? No. (M2)

I go to these classes, right? I have to talk to those guys telling me about how they get urges, [and] I don’t get no urges, no sexual urges around no kids. I don't. I don't get that. Y'know what I'm saying? I really don't. I got a guy in the classroom, I mean, he’s always talking about, he got to stop himself because if he goes near a kid ... and I be looking at him like, 'okay, he’s got a problem', y’know? I don’t have that type of problem. (B8)

\section{Evidence of cognitive transformation}

The achievement of cognitive transformation was detected to varying degrees in 36 participants (82\%), but was almost always viewed as a product of extensive sex-offender-specific treatment. All of these individuals were relatively open about their offending and many had engaged in treatment for a considerable number of years, often continuing to participate beyond that which was prescribed by probation. A continuum of cognitive transformation was identified and a number of men were observed to be at each 'stage'. The first stage was recognizing the harm 
they had caused by committing their offence $(n=5)$. This stage was often punctuated with a great deal of shame and regret. The second stage was having a desire to understand, deeply, the nature of their offence and mostly consisted of detailed descriptions of their offence cycle and the relapse prevention plan $(n=11)$. Next, the utility of treatment was illustrated, with men speaking confidently about how they had integrated what they had learned and now felt they had the tools to live an offence-free life ( $n=8)$. Finally, in some cases (who had been free for the longest time), a new identity was forming where redemption had been achieved or seemed within reach. This final stage was marked by a strong sense of generativity, or a desire to help others $(n=7)$. The men in this final group all volunteered as peer counsellors and mentored other sex offenders.

Before discussing each of these stages in more detail, it is necessary to note that 5 men in the sample were observed to be in transition. They had participated in treatment and used some of the language that the other men used, but they did not appear to have internalized it as fully. These men were all fairly low functioning, had abused children known to them, and did not demonstrate any significant insight into their offending or knowledge of the harm they had caused. Although they all insisted they would not reoffend, they were somewhat less convincing during their interview than the men who could be more easily plotted on the cognitive transformation continuum described earlier. Below are some excerpts from their interviews:

I still got better choices I should be making. I've still got more stuff to be doing as far as the programme goes, but all I know is that I’m doing some so, I guess I'll say I’m doing alright. (M1)

I know [I won’t reoffend] because back then I didn’t realize how much damage it would be to the younger generation. Now I realize that the younger generation is so gullible and don't know anything. (M5)

Five men were categorized as having acknowledged the harm that their offence had caused. This knowledge emerged as an important theme in the narratives of the men. When asked to identity a general turning point in their lives, many participants in this group spoke of the (extremely difficult) moment when they accepted what they had done and took responsibility for their offence. In addition to recognizing the harm they had caused, the men in this group also reported a great deal of shame.

I began to realize through all the therapy that I did, that I created a lot of victims, not just four children. I created a lot of victims, y'know? I began to realize that I had affected their lives permanently. (B4) 
I mean all the time it is in the back of my head. The shame, the guilt, the pain that I am dealing with, the pain that I'm dealing with the flashbacks of what went on. (M14)

Maruna (2001) has argued that 'ex offenders desisting from crime need to account for and understand their criminal pasts (why they did what they did), and they also need to understand why they are now not like that anymore' (in Harris, 2009; 157). This sentiment was expressed by 11 men with a desire for an almost academic level of understanding of sexual deviance and their offending cycle. Many participants described their need to research thoroughly their condition which ultimately led to what they described as an understanding of their past offences and a way of moving on. They said:

I had to get to the bottom of why I did what I did. I had to understand this because I couldn't live with myself like this. So I had to examine each and every time that this took place. I had to do it. (B12)

I feel really good at understanding psychology, understanding human behavior, understanding sexual offending behavior (B18)

The utility of treatment was a common theme and it almost always emerged in an educational context. Participants who spoke of having benefited from treatment felt that they had learned a new way to live and were now 'equipped with the tools' to live an offense-free life:

Group made me see my triggers and that kind of stuff and now it [my offense] won’t happen again. (M6)

I know I won’t reoffend because I have all the tools in my tool chest to keep me out of trouble. I have all the tools from [the treatment program] - that's gonna stay with me a long time. (M22)

Those who reported redemption and optimism for the future were also the ones who expressed confidence in their ability to stay safe and live an offence-free life:

Through living my life a certain way, I can reduce the likelihood. I can manage my life in a way that reduces that likelihood to virtually nil, and that's what I do. (B18)

I look at my medallions [received for each year of participation in the treatment program], and I look at them and say "I made a mistake, but this is to prove that I went through the program.” (M16) 
Of the participants, 7 reflected Maruna's (2001) conceptualization of the professional ex or desistance missionary. These men currently volunteer as mentors to other men in treatment. Their recollections of helping others illustrate the generativity model well.

Since I can't get in the field myself, I might as well just utilize the resources that I know of to help them [recent parolees] get on their feet ... find out how to get their ID, their birth certificate, show them where it is, or show them where to go. (B13)

Even after I graduated the program, I was still there another year and a half as a peer counselor with these guys too.

I volunteer as a mentor for sex offenders ... I try to share my experience to help them with what they are going through. Some of them have just been released, and y'know, I can relate to what that's like, y'know, going to a shopping center and all these choices ... I've been involved in counseling for 15 years and I've heard every story, and so I feel it's useful, and I think coming from a peer in a group, sometimes is more effective, hearing the same thing that a therapist would be saying ... it comes across a bit differently when you've been there yourself and you know what they're thinking, and you know what they're going to say next sometimes. It gives me a sense of being able to put something back, a sense of being productive. (B12)

Some men were almost melodramatic in describing their desires to help others.

And I said, y'know, no matter what, I'm gonna do everything in my power to make sure that I have opportunities to help other people. If I can do anything to help things like this from never happening again, then I am going to. (B4)

I try to help the sick and suffering ... It’s very rewarding ... I know why teachers teach, y'know, because of those 'aha' moments. It’s a rush. It’s refreshing. (B5)

\section{Evidence of informal social control}

The results from the present sample do not support this perspective. No participants attributed their desistance from sexual offending to the positive experience of finding gainful employment or having (or rekindling) a healthy relationship. Instead, the damaging impact of recent legislation on the samples' employment opportunities, available accommodation, and relationship potential surfaced as a particularly strong and negative emergent theme. Moreover, many participants who had achieved various social goods had done so prior to their offence, making them irrelevant 
in a discussion on what variables promote desistance. These results offer empirical support for Göbbels et al.’s (2012) argument that many prisoners are released from custody to worse conditions and with fewer opportunities than they had before their arrest.

Almost three-quarters of the sample $(70 \%, n=31)$ reported having lived with someone in a marital-type relationship at some point in their lives. All but 2 of these men had since divorced, and at the time of the interview only 11 men (25\%) reported being currently married or in a relationship and 6 of them were living with their partners. Although some men reported 'being too old for all that now' ( $n=4)$, or happy to be a 'loner' $(n=5)$, most ( $n=19$ ) of the single men reported feeling lonely, and hoped to find someone, oneday:

I want love. I want to feel like I'm in a sharing relationship, communication, the whole bit. I want it to be like fifty/fifty. (B19)

[My fear is] to not have a relationship. You know, I'm a sex offender now, but I'm young. I'm 26, and it would be nice to have a family before I die. (M25)

Most of these men also expressed fear about having to explain their situation to a potential partner. It was typical for them to be fairly pessimistic about the likelihood that they would date again:

I'm just human you know. I would love to [date] but I'm scared, y'know? I'm scared that if I tell her who I am, maybe they'll say “no”. (B10)

I'd like to [date], but I don't see it happening. We talked about that in group a couple of weeks ago. A guy asked about how he should go about meeting this girl and because he has to also tell her about his record, so he doesn't know how to approach it ... how do you explain, after dating a girl, how do you explain this to her and have her understand? (B17)

Although not a typical sentiment, one man (who had abused his niece on 2 occasions) was somewhat positive about his experience meeting new women:

I went out the other night with a girl that I had met through work and I told her and she just looked at me and was like “Oh really? Okay.” We went out and we had a good time. We went walking around and doing some stuff. She asked me details, y’know, “Well did you rape somebody? Do I have to be worried?” I told her the whole story and I 
assumed that she went [online] and found out ... But I find that most people, when you tell them, y'know, as long as you're honest with them, most people have their own drama, their own stuff going on so ... (M12)

Almost half $(38 \%, n=17)$ of the sample reported having and caring for their young children. Of the men who were fathers, only 5 (17.9\%) currently had access to any of their, now adult, children. At the time of the interview, 2 men were expecting children but both expressed nervousness that the decision to grant them access to their babies was in the hands of their probation officers:

When I told my probation officer [that my girlfriend was pregnant] she was like, “We don't know if you're allowed to or not.” And I was like, “what do you mean? You're gonna tell me I can't see my kid?” So y’know, if that was the case, I'll just tell 'em: “just throw me in jail for the rest of my time [on probation] and I'll see my kid when I'm out." I'm not gonna deal with that, not being able to see my kid, y’know. (M7)

Almost all $(80 \%, n=35)$ of the sample was employed in a steady job prior to their arrest, with many in positions that required considerable skills or training (banking, computing, or academia, for example). Many remarked on the success they enjoyed in their chosen field or the pride they felt from decorated military service. Many men expressed a desire to work and to be productive upon release, but only $10(23 \%)$ had found jobs at the time of the interview. One man was employed full-time (at Dunkin’ Donuts), many considered themselves 'under-employed' (e.g., working at 7-Eleven or as a flagger on a roadwork crew) and none had found work in their chosen field. Many men described the considerable hardships they had experienced while looking for jobs after release:

I've always known what it is to be independent and self-sufficient and capable and now I feel handicapped because I still am smart and educated and capable but I'm handicapped because now if I apply for a job I get scrutinized and my criminal history gets looked at. (B11)

I want to work because sometimes I find myself being bored out of my mind, and even though I read and do things to keep busy, it’s just that I’ve been working since I got out of high school ... I don’t like it 'cos I don't feel like I'm doing anything constructive for society. (B9)

In three out of the five interviews that I had, the company wanted to hire me, and then the background check comes in ... I don't believe my offense should preclude me from working in the pharmaceutical research and development field. (B6) 


\section{A note on negative cases}

In addition to discussing themes of desistance, it is important to identify the 'deviant' or 'negative' case (Becker, 1998), that is, the uncovering of evidence of the opposite of an anticipated theme (Harris, 2014b). Thus, it is necessary to note that 2 men denied benefiting at all from treatment and were extremely vocal in complaining about their undeserved 'status' as a sex offender. These men who were convicted of a single offence (in both cases, representing multiple incidents against the same victim), repeatedly emphasized the situational nature of their crime, expressed their resentment of the label of sex offender for a 'single mistake' and did not believe that their behaviour warranted mandatory treatment. (Many of the men in the other desistance groups were also convicted of a single offence and struggled with the sex offender label, but had clearly embraced therapy more completely.) Although these 2 negative cases made it very clear they would never again commit a sexual offence, they did not do so using a narrative of natural desistance or cognitive transformation and are not included in the analysis above.

\section{Discussion}

Participants reported being grateful for the chance to share their experiences and many commented on the validation they felt from being listened to. Sharing their stories also helped them feel as if they had a voice, and many expressed hope that their involvement would lead to positive policy and legislative change. As these men discussed their hopes and fears for the future, it seems appropriate to share their perspectives on redemption. Consistent with existing desistance literature, there was a strong emphasis in many of the narratives on the possibility of change. I close the chapter with some of their final thoughts:

I guess the only other thing I want to say is, contrary to popular belief, people can change and that's not just the alcoholic, it's not just the guy that did drugs as a kid who is now clean and sober and let’s give him a job - sex offenders can change and stop doing what they did and stop feeling and thinking the way they felt and thought. I talked to someone who said that as soon as an adult touches a child they cease to be human and they should cease to have human rights. And this was before I had ever confessed and I thought "why are they devoid of the opportunity to repent and change and do good when other people are given that chance? You know? What makes us any different?” (M22)

Contrary to public opinion (and perhaps some professional assumptions), these results suggest that recidivism is not an inevitable consequence of returning a sexual offender to the community. The great majority of sex offenders 
desist from offending (with or without formal or informal intervention) and the logical next question is "why?” or "how are they desisting in spite of a lack of social support?”

Some offenders will desist on their own, regardless of formal assistance or criminal justice system intervention. Some will benefit immensely from sex-offender-specific treatment, and others might profit simply from reconnecting with their family of origin, or from the opportunity to earn an honest living. Still others, overcome by the stigma of their offence and now understanding the consequences of their crimes, may decide quite rationally to never offend again, simply to avoid returning to custody. And some will indeed warrant the restrictive approaches that have become characteristic of enhanced community corrections, such as electronic monitoring, residence restrictions, or curfews. It is my opinion that the number of offenders who warrant those restrictive approaches is very small. This amounts to a significant commitment of expensive resources that address the narrowest of circumstances. None of these initiatives accommodate, encourage, or even acknowledge the possibility of desistance. Further, as mounting research now illustrates the damaging legal, practical, social, and psychological consequences of these laws, it is patently clear that they exacerbate risk factors and increase recidivism. Focusing on this serious but small subsample to the exclusion of everyone else provides a massive disservice to the many lowlevel, versatile, non-serious, intermittent, situationally induced sexual offenders who will soon be released, show potential for success and desistance, and are desperate for assistance when the prison door closes behind them.

There is much we can do to better assist men convicted of sexual offences as they re-enter society, but the most promising recommendations will require a significant change in focus. For too long the field has been consumed with risk, relapse, and recidivism. I suggest inverting this paradigm to instead concentrate on rehabilitation, recovery, and redemption. If we encourage the pursuit of mastery by providing ways to spend time productively (whether through employment, hobbies, sport, or service), and foster intimacy by facilitating the creation or reunification of positive prosocial relationships (with peers, family members, partners, or colleagues), and achieve each of these with the more global goal of facilitating natural desistance and identity change, we will be one step closer to reaching our goal of making society safer.

\section{References}

Atkinson, R. (1998). The life story interview: Qualitative research methods (series 44). Thousand Oaks, CA: Sage Publications. 
Barbaree, H. E. and Blanchard, R. (2008). Sexual deviance over the lifespan: Reduction in deviant sexual behavior in the aging sex offender. In D. R. Laws and W. T. O’Donohue. Sexual deviance: Theory, assessment, and treatment (pp. 37-60). New York: Guilford Press.

Becker, H. S. (1998). Tricks of the trade: How to think about your research while you're doing it. Chicago, IL: University of Chicago Press.

Farmer, M., Beech, A. and Ward, T. (2011). Assessing desistance in child molesters: A qualitative analysis. Journal of Interpersonal Violence,27(5) 1-21.

Farrall, S. (2010). A short history of the investigation into the ending of the criminal career. Safer Communities, 9(3), 9-16.

Farrall, S., Hough, M., Maruna, S. and Sparks, R. (2011). Escape routes: Contemporary perspectives on life after punishment. Abingdon: Routledge.

Finn, P. (1997). Sex offender community notification, research in action. Washington, DC: US

Department of Justice, National Institute of Justice (NCJ 162364).

Francis, B. and Soothill, K. (2000). Does sex offending lead to homicide? Journal of Forensic Psychiatry, 11(1), 49-61.

Giordano, P., Cernkovich, S. and Rudolph, J. (2002). Gender, crime, and desistance: Toward a theory of cognitive transformation. American Journal of Sociology, 107(4), 990-1064.

Göbbels, S., Ward, T. and Willis, G. (2012). An integrative theory of desistance from sex offending. Aggression and Violent Behavior, 17( ), 453-462.

Hanson, R. K. (2002). Recidivism and age: Follow-up data from 4,673 sexual offenders. Journal of Interpersonal Violence, 17(10), 1046-1062.

Harris, D. A. (2014a) Theories of desistance from sexual offending. In T. Ward, D. Polaschek and A. Beech (eds.). Theories of sexual offending (2nd ed.) (pp. ). West Sussex: John Wiley \& Sons.

Harris, D. A. (2014b). Desistance from sexual offending: Findings from 21 life history narratives. Journal of Interpersonal Violence,29(9) 1554-1578

Harris, D. A., Smallbone, S., Dennison, S. and Knight, R. A. (2009). Offense specialization and versatility in the criminal histories of adult male sexual offenders referred for civil commitment. Journal of Criminal Justice, 37( ), 37-44. 
Harris, M. K. (2009). Identity change through the transformation model of the public safety initiative of LIFERS, Inc. In B. Veysey, J. Christian and D. Martinez (eds). How offenders transform their lives (pp.143-164 ). Portland, OR: Willan Publishing.

Healy, D. (2010). The dynamics of desistance: Charting pathways through change. Portland, OR: Willan Publishing.

Janus, E. and Walbek, N. (2000). Sex offender commitments in Minnesota: A descriptive study of second-generation commitments. Behavioral Sciences and the Law, 18(2-3), 343-374.

Jeglic, E., Calkins Mercado, C. and Levenson, J. (2012). The prevalence and correlates of depression and hopelessness among sex offenders subject to community notification and residence restriction legislation. American Journal of Criminal Justice, 37(1), 46-59.

Klein, M. (1984). Offence specialisation and versatility among juveniles. British Journal of Criminology, 24 (2), 185-194.

Knight, R. A. and Thornton, D. (2007). Evaluating and improving risk assessment schemes for sexual recidivism: A long-term follow-up of convicted sexual offenders (Final Report: NCJ 217618).

La Fond, J. (2000). The future of involuntary civil commitment in the USA after Kansas v. Hendricks. Behavioural Sciences and the Law, 18(2-3), 153-167.

Laub, J. and Sampson, R. (2003). Shared beginnings, divergent lives: Delinquent boys to age 70. Cambridge, MA: Harvard University Press.

Laws, R. and Ward, T. (2011). Desistance from sex offending: Alternatives to throwing away the keys. New York: The Guilford Press.

Lieb, R., Quinsey, V., \& Berliner, L. (1998). Sexual Predators and Social Policy. Crime and Justice, 23, 43-114.

Maruna, S. (2001). Making good: How ex-convicts reform and rebuild their lives. Washington DC: American Psychological Association.

McAdams, D. (1993). The stories we live by: Personal myths and the making of the self. New York: The Guildford Press.

Petersilia, J. (2004) When prisoners come home: Parole and prisoner re-entry. New York: Oxford University Press.

Petrunik, M. (2002) Managing unacceptable risk: Sex offenders, community response, and social policy in the United States and Canada. International Journal of Offender Therapy and Comparative Criminology, 46(4), 483-511. 
Sampson, R. and Laub, J. (1993). Crime in the making: Pathways and turning points through life. London: Harvard University Press.

Scoones, C., Willis, G. and Grace, R. (2012). Beyond static and dynamic risk factors: The incremental validity of release planning for predicting sex offender recidivism. Journal of Interpersonal Violence, 27(2), 222-238.

Simon, L. (1997a). Do criminal offenders specialize in crime types? Applied and Preventive Psychology, 6(1), 35-53.

Simon, L. (1997b). The myth of sex offender specialization: An empirical analysis. New England Journal on Criminal and Civil Confinement, 23( ), 387-403.

Simon, L. (2000). An examination of the assumptions of specialization, mental disorder, and dangerousness in sex offenders. Behavioural Sciences and the Law, 18(2-3), 275-308.

Ward, T. and Marshall, W. L. (2004). Good lives, etiology and the rehabilitation of sex offenders: A bridging theory. Journal of Sexual Aggression: Special Issue: Treatment \& Treatability, 10( ), 153-169.

Willis, G., Levenson, J. and Ward, T. (2010). Desistance and attitudes towards sex offenders: Facilitation or hindrance? Journal of Family Violence, 25( ), 545-556.

Wilson, J. and Herrnstein, R. (1985). Crime and Human Nature. New York: The Free Press. 